\title{
Chronic morphine use does not induce peripheral tolerance in a rat model of inflammatory pain
}

\author{
Christian Zöllner, ${ }^{1}$ Shaaban A. Mousa, ${ }^{1}$ Oliver Fischer, ${ }^{1}$ Heike L. Rittner, ${ }^{1}$ Mohammed Shaqura, ${ }^{1}$ \\ Alexander Brack, ${ }^{1}$ Mehdi Shakibaei, ${ }^{2}$ Waltraud Binder, ${ }^{1}$ Florian Urban, ${ }^{1}$ \\ Christoph Stein, ${ }^{1}$ and Michael Schäfer ${ }^{1}$
}

\begin{abstract}
${ }^{1}$ Klinik für Anaesthesiologie und operative Intensivmedizin, Charité — Universitätsmedizin Berlin, Campus Benjamin Franklin, Berlin, Germany. ${ }^{2}$ Institut für Anatomie, Ludwig-Maximilians Universität München, Munich, Germany.
\end{abstract}

\begin{abstract}
Although opioids are highly effective analgesics, they are also known to induce cellular adaptations resulting in tolerance. Experimental studies are often performed in the absence of painful tissue injury, which precludes extrapolation to the clinical situation. Here we show that rats with chronic morphine treatment do not develop signs of tolerance at peripheral $\mu$-opioid receptors ( $\mu$-receptors) in the presence of painful CFA-induced paw inflammation. In sensory neurons of these animals, internalization of $\mu$-receptors was significantly increased and $G$ protein coupling of $\mu$-receptors as well as inhibition of cAMP accumulation were preserved. Opioid receptor trafficking and signaling were reduced, and tolerance was restored when endogenous opioid peptides in inflamed tissue were removed by antibodies or by depleting opioid-producing granulocytes, monocytes, and lymphocytes with cyclophosphamide (CTX). Our data indicate that the continuous availability of endogenous opioids in inflamed tissue increases recycling and preserves signaling of $\mu$-receptors in sensory neurons, thereby counteracting the development of peripheral opioid tolerance. These findings infer that the use of peripherally acting opioids for the prolonged treatment of inflammatory pain associated with diseases such as chronic arthritis, inflammatory neuropathy, or cancer, is not necessarily accompanied by opioid tolerance.
\end{abstract}

\section{Introduction}

Opioids are the most widely used drugs in acute and chronic pain. Long-term application of opioids can result in pharmacological tolerance in animals, i.e., a decreased effect with prolonged administration of a constant dose $(1,2)$. However, surprisingly little data document opioid tolerance in humans $(3,4)$. Some clinical publications claim that opioid tolerance does not develop frequently in patients with chronic pain resulting from cancer $(5,6)$ or nonmalignant tissue injury $(7,8)$, both of which are usually accompanied by inflammation. In inflammatory pain a substantial component of opioid analgesia is mediated via opioid receptors on peripheral sensory neurons $(9,10)$. Consequently, we chose to examine the development of tolerance at peripheral $\mu$-opioid receptors ( $\mu$-receptors) in animals with and without chronic inflammatory pain.

Regulation of intracellular receptor trafficking is of fundamental importance for the function of opioid receptors. Receptor internalization and recycling to the membrane following agonist exposure is a well-documented response for a wide variety of $G$ protein coupled receptors (11) and has been proposed to underlie the rapid recovery of opioid responsiveness after acute agonist application (12). The enhancement of opioid receptor recycling provides receptor recuperation and counteracts the development of opioid tolerance (13). However, there are differences between ligands and between in vitro and in vivo conditions. For example, morphine-activated

Nonstandard abbreviations used: $B_{\max } \mathrm{G}$ protein, total number of $\mathrm{G}$ protein binding; $\mathrm{B}_{\max \mu \text {-receptor, }}$ total number of $\mu$-receptor binding; CTX, cyclophosphamide; DAMGO, $\left[\mathrm{D}-\mathrm{Ala}^{2}, N\right.$-Me-Phe ${ }^{4}, \mathrm{Gly}^{5}$-ol] enkephalin; DRG, dorsal root ganglion(s); END, $\beta$-endorphin; FSK, forskolin; $\left[{ }^{35} \mathrm{~S}\right] \mathrm{GTP} \gamma \mathrm{S},\left[{ }^{35} \mathrm{~S}\right]$ guanosine-5'-O-( $\gamma$-thio)-triphosphate; i.pl., intraplantar; PMN, polymorphonuclear cell; PPT, paw pressure threshold.

Conflict of interest: The authors have declared that no conflict of interest exists. Citation for this article: J. Clin. Invest. 118:1065-1073 (2008). doi:10.1172/JCI25911. opioid receptors in heterologous cells (14) and neurons (15) are relatively resistant to this regulatory process. Potential mechanisms include a lower degree of $\mu$-receptor phosphorylation (16) or slower phosphorylation kinetics (17) than receptors activated by the endogenous opioid peptides endorphin or enkephalin.

In inflammatory pain endogenous ligands of peripheral opioid receptors have been identified in resident immune cells of the injured tissue $(9,10)$. These cells exhibit precursor mRNA, processing enzymes, vesicular localization, and calcium-regulated release of opioid peptides $(9,18)$. In the present study, we therefore investigated the effect of ongoing inflammatory pain on the development of $\mu$ receptor tolerance, endocytosis, and signaling in dorsal root ganglion (DRG) neurons. Chronic s.c. morphine treatment, a standard regimen to induce opioid tolerance, was used in animals with and without paw inflammation. Paw withdrawal thresholds to noxious pressure were measured after acute intraplantar (i.pl.) injections of small, systemically ineffective doses of fentanyl, an agonist capable of activating peripheral $\mu$-receptors both in inflamed and noninflamed tissue (19). We then examined opioid receptor trafficking, signaling, and cellular adaptations using immunohistochemistry, opioid receptor binding, $\mathrm{G}$ protein coupling, and cAMP formation. To study the role of endogenous opioid peptides in the inflamed tissue, they were eliminated by antibodies or by depleting opioid-producing immune cells with cyclophosphamide (CTX). Our results indicate that the continuous presence of endogenous opioids in inflamed tissue increases recycling and preserves signaling of $\mu$-receptors in sensory neurons and thereby counteracts the development of tolerance.

\section{Results}

Morphine pretreatment induces tolerance at peripheral opioid receptors in animals without inflammatory pain but not in animals with inflamma- 


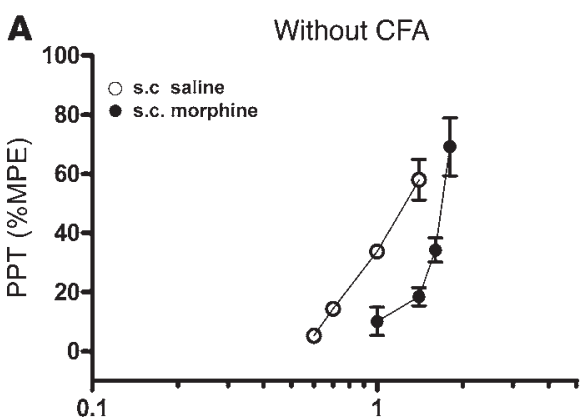

i.pl. fentanyl $(\mu \mathrm{g})$

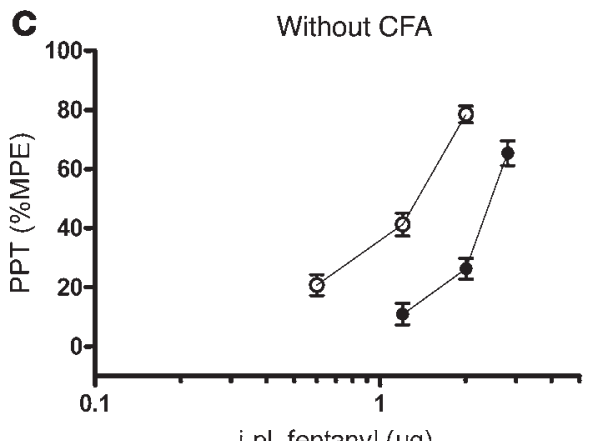

i.pl. fentanyl $(\mu \mathrm{g})$

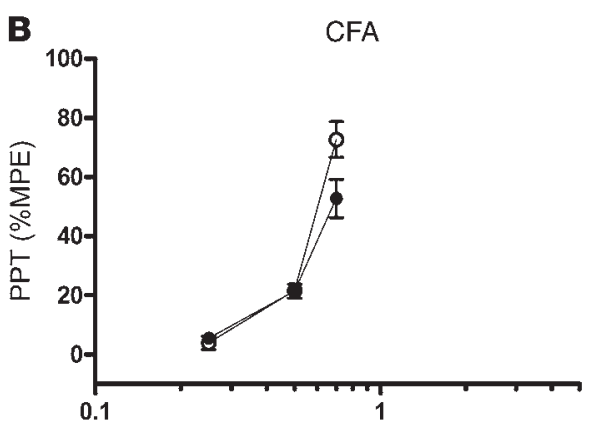

i.pl. fentanyl $(\mu g)$

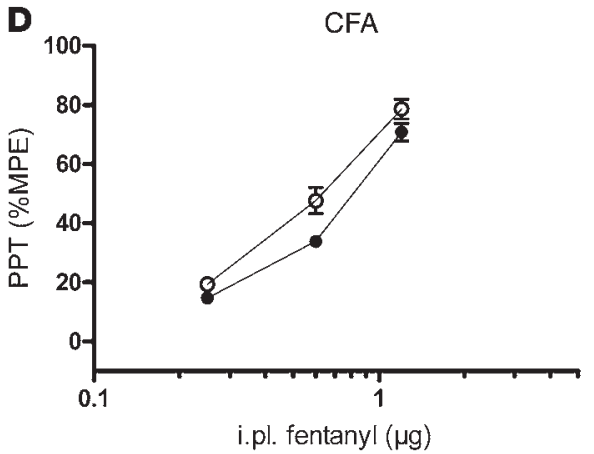

\section{Figure 1}

Dose-response curves of acute i.pl. fentanyl antinociception in animals without and with hindpaw CFA inflammation. (A) Without paw inflammation the $\mathrm{ED}_{50}$ for elevation of PPT was significantly lower in s.c. saline-pretreated than in s.c. morphine-pretreated animals (ANOVA, $P<0.001$ ). (B) In the presence of paw inflammation, no significant difference in $\mathrm{ED}_{50}$ was detectable between chronic s.c. morphine and s.c. saline pretreatment (ANOVA, $P>0.05$ ). SEM was occasionally smaller than symbol size. (C) Repeated pretreatment with i.pl. fentanyl ( $2 \mu \mathrm{g}$ twice daily) for 4 days shifted the dose-response curve after acute i.pl. fentanyl application significantly to the right, confirming the development of peripheral opioid tolerance (ANOVA, $P<0.05$ ). (D) In CFA animals pretreated with chronic i.pl. fentanyl, the $\mathrm{ED}_{50}$ of acute i.pl. fentanyl antinociception did not significantly change, confirming a lack of peripheral opioid tolerance (ANOVA, $P>0.05$ ). The applied doses of i.pl. fentanyl did not change PPT in contralateral paws (data not shown), indicating that they were not systemically effective and did not activate central opioid receptors. MPE, maximum possible effect. tory pain. First we pretreated animals with morphine $(10 \mathrm{mg} / \mathrm{kg}$ s.c. twice daily) for 4 days. Subsequently, higher doses $\left(E_{50}\right)$ of acutely applied i.pl. fentanyl were necessary to achieve the same peripheral analgesic effects (i.e., elevations of paw pressure thresholds [PPTs]) as in animals without s.c. morphine treatment, indicating the development of peripheral opioid tolerance (Figure 1A and Table 1). We then examined animals with paw inflammation induced by i.pl. CFA, which leads to reduced baseline PPT (hyperalgesia) and to increased peripheral opioid analgesia (reviewed in ref. 9). In CFA animals, chronic pretreatment with s.c. morphine did not significantly change the $\mathrm{ED}_{50}$ of i.pl. fentanyl antinociception, indicating a lack of peripheral opioid tolerance (Figure 1B and Table 1). We obtained similar results after repeated pretreatment with i.pl. fentanyl. Fentanyl ( $2 \mu \mathrm{g}$ i.pl. twice daily) was used because it is a lipophilic opioid that readily penetrates the perineural barrier to access opioid receptors on sensory neurons in noninflamed subcutaneous tissue (19). Chronic i.pl. fentanyl pretreatment for 4 days shifted the dose-response curve significantly to the right for animals without CFA inflammation, indicating the development of peripheral opioid tolerance (Figure 1C and Table 1). This shift was not detected in animals with CFA inflammation, indicating a lack of peripheral opioid tolerance (Figure 1D and Table 1).

Morphine pretreatment promotes internalization of $\mu$-receptors in DRG neurons of animals with inflammatory pain. To examine whether the availability of $\mu$-receptors on the surface of DRG neurons was changed by chronic morphine pretreatment or paw inflammation, we determined $\mu$-receptor binding in membrane preparations of these neurons. This assay quantifies surface receptors but not endocytosed receptors. Saturation binding of the $\mu$-receptor ligand $\left[{ }^{3} \mathrm{H}\right]\left[\mathrm{D}-\mathrm{Ala}^{2}, N\right.$ Me-Phe $e^{4}$,Gly ${ }^{5}$-ol $]$ enkephalin $\left(\left[{ }^{3} \mathrm{H}\right] \mathrm{DAMGO}\right)$ showed similar $\mathrm{K}_{\mathrm{d}}$ in all DRG regardless of CFA or morphine pretreatment (data not shown). In rats without CFA, the total number of $\mu$-receptor binding $\left(B_{\max \mu \text {-receptor }}\right)$ on DRG did not differ between animals with and without chronic morphine pretreatment $(t$ test, $P>0.05$ ) (Table 2 and Figure 2A). However, in rats with CFA inflammation, the $\mathrm{B}_{\max \mu \text {-receptor }}$ on DRG was significantly decreased by morphine pretreatment ( $t$ test, $P<0.001$; Table 2 and Figure $2 \mathrm{~F}$ ). We obtained similar results after repeated pretreatment with i.pl. fentanyl. In animals without CFA inflammation, the $B_{\max \mu \text {-receptor }}$ did not differ (i.pl. saline versus fentanyl pretreatment, $25 \pm 1.7$ versus $29 \pm 1.8$ $\mathrm{fmol} / \mathrm{mg}$ protein; $t$ test, $P>0.05$ ), whereas in rats with CFA inflammation the $B_{\max \mu \text {-receptor was significantly lowered by i.pl. fentanyl }}$ pretreatment (i.pl. saline versus fentanyl pretreatment, $47 \pm 4.8$ versus $36 \pm 2.0 \mathrm{fmol} / \mathrm{mg}$ protein; $t$ test, $P<0.05)$. To examine whether the surface availability of $\mu$-receptors was correlated to receptor trafficking, we assessed their internalization in cultured and native DRG neurons. In DRG from animals without inflammation, $\mu$-receptors were predominantly located at the cell surface,
Table 1

Antinociceptive potency $\left(\mathrm{ED}_{50}\right)$ of i.pl. fentanyl after pretreatment with s.c. morphine or i.pl. fentanyl

\begin{tabular}{lcccc} 
Parameter & \multicolumn{2}{c}{ No inflammation } & \multicolumn{2}{c}{ CFA inflammation } \\
& & & & \\
& Saline & Morphine & Saline & Morphine \\
$\mathrm{ED}_{50}(\mu \mathrm{g})$ & $1.0 \pm 0.1$ & $1.6 \pm 0.1^{\mathrm{A}}$ & $0.5 \pm 0.03$ & $0.6 \pm 0.02$ \\
& Saline & Fentanyl & Saline & Fentanyl \\
$\mathrm{ED}_{50}(\mu \mathrm{g})$ & $1.3 \pm 0.1$ & $2.2 \pm 0.3^{\mathrm{A}}$ & $0.6 \pm 0.2$ & $0.7 \pm 0.1$
\end{tabular}
CFA inflammation without endogenous opioids

Saline/CTX Morphine/CTX

$0.8 \pm 0.03 \quad 1.9 \pm 0.1^{\mathrm{A}}$

Saline/Ab Morphine/Ab

$0.4 \pm 0.1 \quad 1.8 \pm 0.3^{\mathrm{A}}$ 


\section{Table 2}

$B_{\max \mu \text {-receptor }}$ and $B_{\max G \text { protein }}$ in animals with or without CFA inflammation, pretreated with s.c. saline or morphine

\section{Parameter}

Without CFA

$B_{\text {max } \mu \text {-receptor }}(\mathrm{fmol} / \mathrm{mg})$

$B_{\max }$ G protein $(\mathrm{fmol} / \mathrm{mg})$

Amplification factor

\section{$26 \pm 1.7$ \\ $335 \pm 33$}

13

\section{Without CFA/ \\ with morphine}

$28 \pm 2.0$
$230 \pm 21^{A}$
8

\section{With CFA}

$50 \pm 4.1$

$488 \pm 62$

10

(data not shown). The total number of DAMGO-activated $\mathrm{G}$ proteins (apparent $\mathrm{B}_{\max \mathrm{G} \text { protein }}$ ) was significantly lower after chronic morphine than after saline pretreatment, regardless of the absence (Fig-

both without (Figure 2, B and C) and with morphine pretreatment (Figure 2, D and E). However, in animals with CFA inflammation, $\mu$-receptors were, for the most part, removed from the neuronal cell surface. This endocytosis appeared more pronounced in the presence (Figure 2, I and J) than in the absence (Figure 2, G and $\mathrm{H}$ ) of chronic morphine pretreatment.

Morphine pretreatment does not change $\mu$-agonist-induced G protein coupling and cAMP reduction in DRG neurons of animals with inflammatory pain. To examine whether morphine pretreatment influenced opioid receptor signaling, we assessed $G$ protein coupling and cAMP production. Saturation analysis of DAMGO-stimulated $\left[{ }^{35} \mathrm{~S}\right]$ guanosine-5'-O( $\gamma$-thio)-triphosphate $\left(\left[{ }^{35} \mathrm{~S}\right] \mathrm{GTP} \gamma \mathrm{S}\right)$ binding was used to determine the equilibrium dissociation constant $\left(\mathrm{K}_{\mathrm{d}} \mathrm{G}\right.$ protein) of $\left[{ }^{35} \mathrm{~S}\right] \mathrm{GTP} \gamma \mathrm{S}$ for the activated $\mathrm{G}$ protein and the total number of $G$ protein binding $\left(B_{\max } G\right.$ protein $)$ to the $\mu$ receptor (see also Supplemental Methods; supplemental material available online with this article; doi:10.1172/ JCI25911DS1). Similar $\mathrm{K}_{\mathrm{d}}$ for $\mathrm{G}$ proteins at $\mu$-receptors were found in all DRG regardless of pretreatment

\section{Figure 2}

$\mu$-Receptors on DRG neurons. [ $\left.{ }^{3} \mathrm{H}\right] \mathrm{DAMGO}$ saturation binding in DRG membranes from animals without (A) and with (F) hindpaw CFA inflammation. (A) In animals without CFA inflammation, the number of $\mu$-receptors did not differ significantly between untreated (set at $100 \%$ ) and s.c. morphine-pretreated animals ( $t$ test, $P>0.05$ ). (F) In animals with CFA inflammation, the number of $\mu$-receptors was significantly lower in s.c. morphine-pretreated compared with untreated animals (set at $100 \%)\left(t\right.$ test; $\left.{ }^{*} P<0.001\right)$. Representative immunohistochemical staining of $\mu$-receptors in cultured DRG neurons (B, D, G, and I) and native DRG sections (C, E, H, and J) processed for confocal microscopy. In DRG from animals without CFA inflammation (B-E), $\mu$-receptors (indicated by arrows) were primarily localized to the plasma membrane both without (B and C) and with (D and E) chronic s.c. morphine pretreatment. In animals with CFA inflammation $(\mathbf{G}-\mathbf{J})$, $\mu$-receptors are redistributed to the cytoplasm. This endocytosis appears less pronounced without $(\mathbf{G}$ and $\mathbf{H}$ ) than with (I and $\mathbf{J})$ chronic s.c. morphine pretreatment. Each optical section was also individually displayed to enable analysis from the top surface to the bottom of the cell. Scale bar: $5 \mu \mathrm{M}$ (B, D, G, and I); $10 \mu \mathrm{M}$ (C, E, H, and J). ure $3 \mathrm{~A}$ ) or presence (Figure $3 \mathrm{~B}$ ) of paw inflammation ( $t$ test, $P<0.05$; Table 2 and Figure 3, A and B). However, since after chronic morphine pretreatment the number of surface $\mu$-receptors was reduced in animals with (but not without) CFA inflammation, the relative number of activated $G$ proteins per surface $\mu$-receptor (amplification factor) did not decrease in the CFA-treated group, whereas it did decrease in the group without CFA (Table 2

and Supplemental Methods).
$31 \pm 5.2$

$290 \pm 29$

9
Regardless of pretreatment, the cAMP content in DRG increased significantly after forskolin (FSK) stimulation (Figure 4, A-D). This cAMP increase was significantly reduced by the acute application of morphine both in DRG of animals without (Figure 4A) and with (Figure 4B) CFA-induced inflammation. In DRG of animals chronically pretreated with s.c. morphine, acute opioid application no longer decreased the cAMP accumulation in the absence of CFA inflammation (ANOVA, $P>0.05$; Figure 4C) but
A

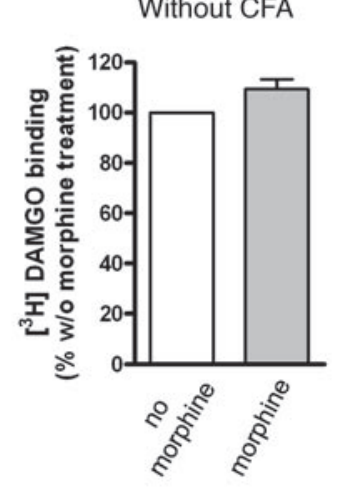

$\mathbf{F}$

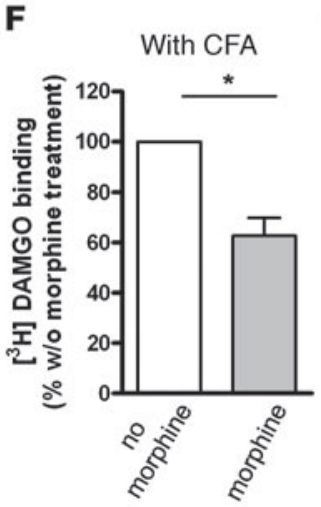

Without CFA/without morphine
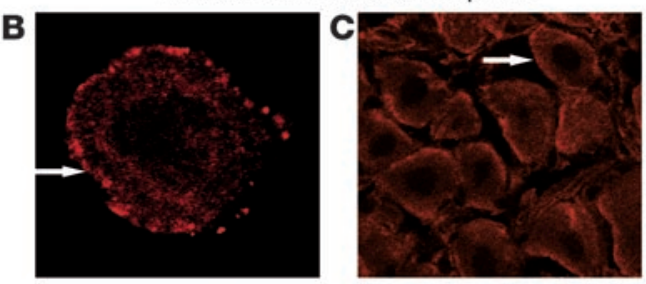

Without CFA/with morphine
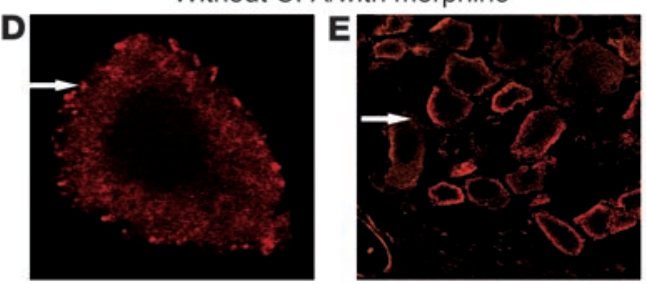

CFA/without morphine
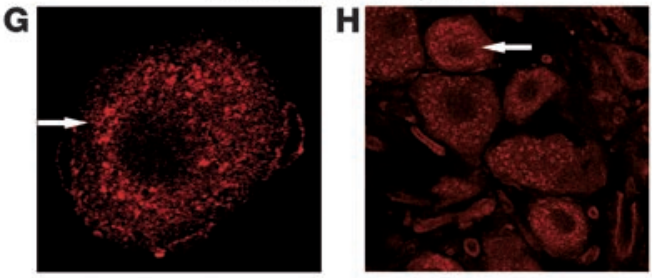

CFA/with morphine
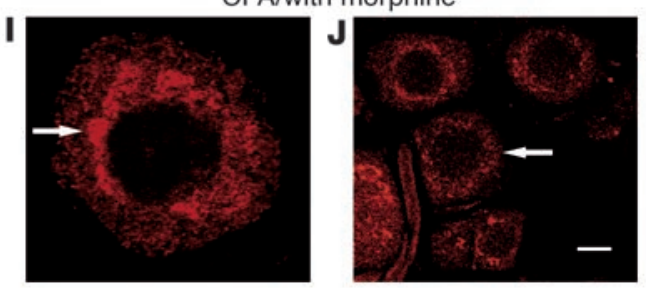
A

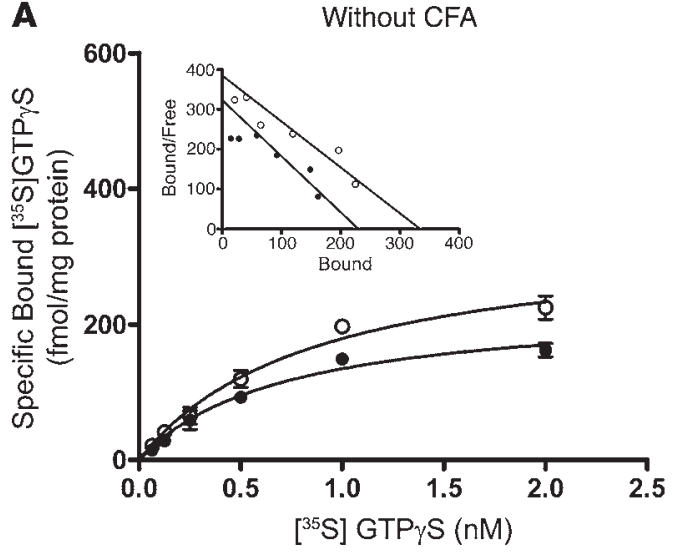

B

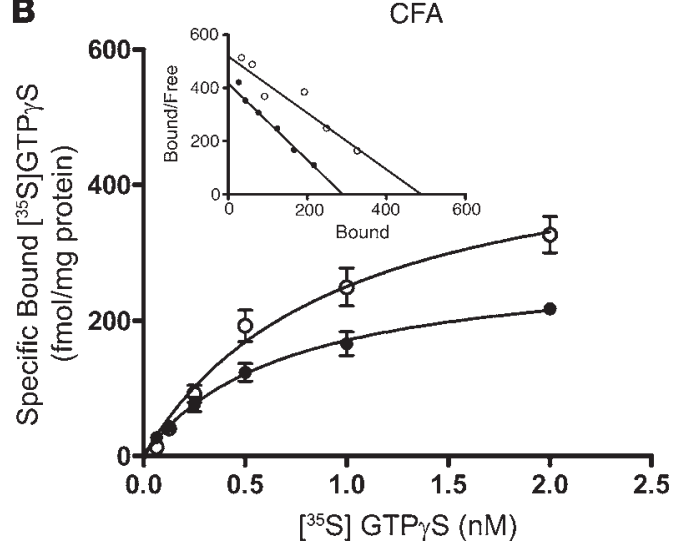

Figure 3

Analysis of DAMGO-stimulated $(10 \mu \mathrm{M})\left[{ }^{35} \mathrm{~S}\right] \mathrm{GTP} \gamma \mathrm{S}$ saturation binding in DRG membranes from animals without and with CFA-induced inflammation pretreated with daily injections of s.c. saline or morphine for 4 days. (A) Without CFA-induced inflammation. (B) With CFA-induced inflammation. DAMGO-stimulated specific $\left.{ }^{35} \mathrm{~S}\right] \mathrm{GTP} \gamma \mathrm{S}$ binding was significantly lower in morphine-treated than in saline-treated animals in both cases $(t$ test, $P<0.05)$. Insets: Data were plotted according to the traditional Scatchard analysis (see Supplemental Methods), in which the $x$ axis shows specific binding and the $y$ axis shows specific binding divided by free radioligand concentration. From the Scatchard line, $B_{\max } G$ protein is the $x$ intercept.

did so in the presence of CFA inflammation (ANOVA, $P<0.01$; Figure 4D). Thus, during chronic morphine pretreatment both $\mathrm{G}$ protein coupling to $\mu$-receptors and $\mu$-agonist-induced inhibition of cAMP production are preserved in sensory neurons of animals with but not without painful paw inflammation.

Role of endogenous opioid peptides in the development of opioid tolerance. CTX treatment depletes opioid-containing immune cells and counteracts morphine-induced internalization of $\mu$-receptors in DRG neurons of animals with inflammatory pain. Consistent with our previous studies (18), immunoelectron microscopy revealed $\beta$-endorphin-containing (END-containing) macrophages (Figure 5, A and D), polymorphonuclear cells (PMNs) (Figure 5B), and lymphocytes (Figure 5, C and E) in s.c. tissue of inflamed paws. END was contained in secretory granules packed in membranous structures. Preabsorption of antibody against END with 5 $\mu \mathrm{g} / \mathrm{ml}$ purified END completely abolished immunostaining (data not shown). To assess the involvement of these opioid peptide-containing immune cells in tolerance, we first treated animals with CFA inflammation by systemic i.p. application of CTX. As quantified by flow cytometry, CTX treatment completely depleted macrophages, PMNs, T lymphocytes, and opioid-containing cells in inflamed paws (all groups, $t$ test, $P<0.01$ ) (Figure 6, A-D). To examine whether the lack of endogenous opioid peptides can interfere with the availability of $\mu$-receptors on the surface of DRG neurons after

\section{Figure 4}

Content of cAMP in DRG cells from animals without and with hindpaw CFA inflammation pretreated with s.c. morphine. (A-D) Basal cAMP was significantly lower in the absence of FSK in comparison with FSK treatment. Acute opioid application significantly decreased FSK-stimulated cAMP production in comparison with FSK treatment alone in DRG cells of animals with CFA (B) and CFA/morphine pretreatment (D) (ANOVA, ${ }^{*} P<0.01$ ), but not in morphine-pretreated animals without CFA inflammation (C) (ANOVA, $\left.{ }^{\#} P>0.05\right)$. Values are expressed as percentages of FSK-stimulated (100\%) cAMP levels. chronic s.c. morphine treatment, we determined $\mu$-receptor binding on membrane preparations of these cells. In rats with CFA inflammation and CTX treatment, the number of $\mu$-receptors on DRG cells did not differ between animals with $(46.4 \pm 5.3 \mathrm{fmol} /$ $\mathrm{mg}$ protein) and without $(43.6 \pm 4.0 \mathrm{fmol} / \mathrm{mg}$ protein $)$ chronic morphine pretreatment ( $t$ test, $P>0.05$; Figure $6 \mathrm{E}$ ). Consistently, immunohistochemistry in cultured DRG neurons from animals with CFA inflammation and CTX revealed that $\mu$-receptors were largely located near the plasma membrane both in the absence (Figure 6, G and $\mathrm{H}$ ) and presence (Figure 6, I and J) of chronic s.c. morphine pretreatment. This is in opposition to our findings in CFA animals without CTX (Figure 2, G-J). Thus, immunosuppression with CTX abolished morphine-induced opioid receptor internalization in DRG neurons of animals with inflammatory pain.
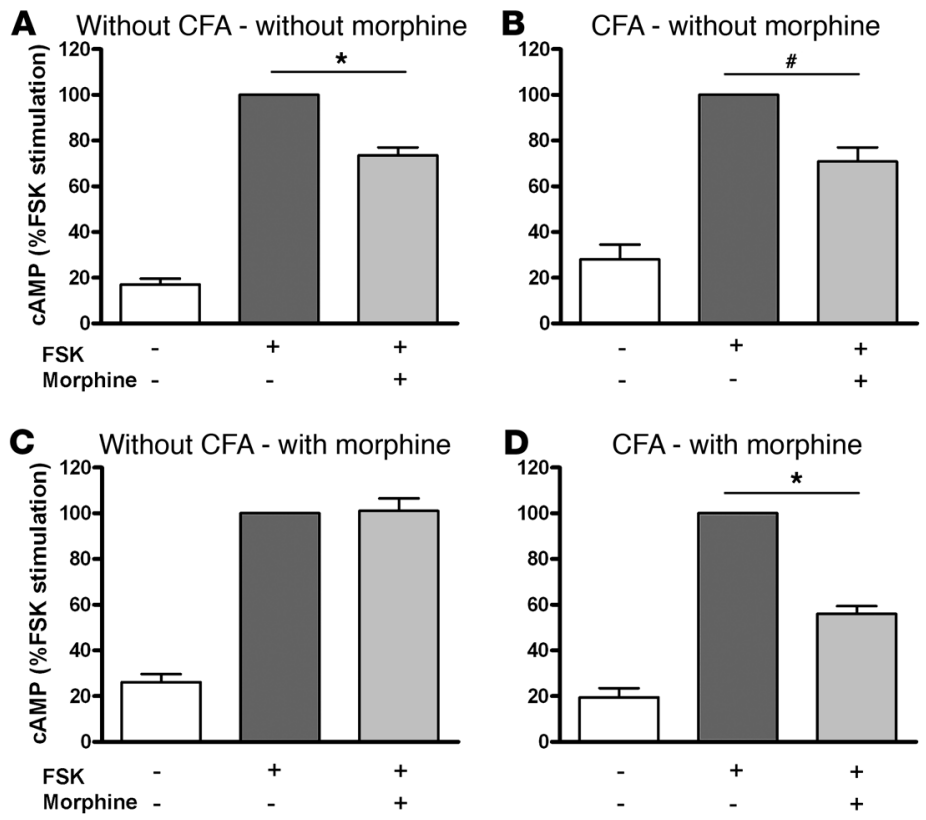
A

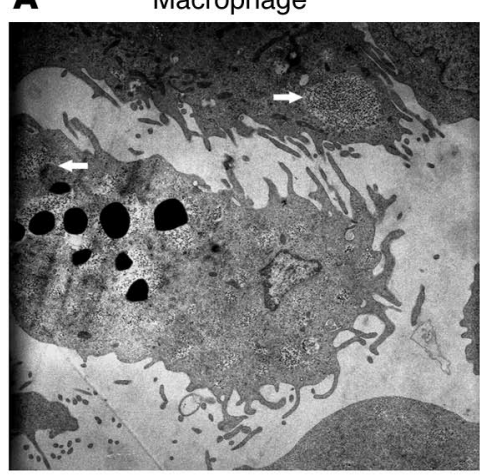

D

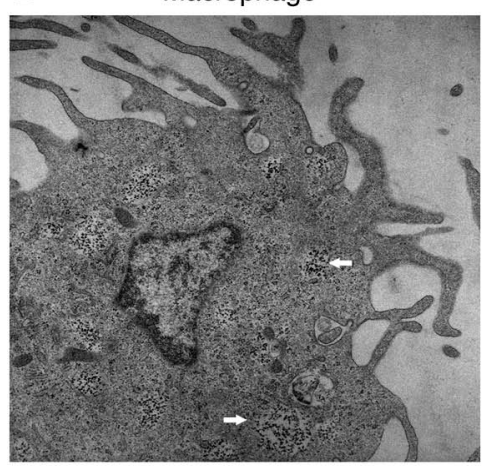

Macrophage
B

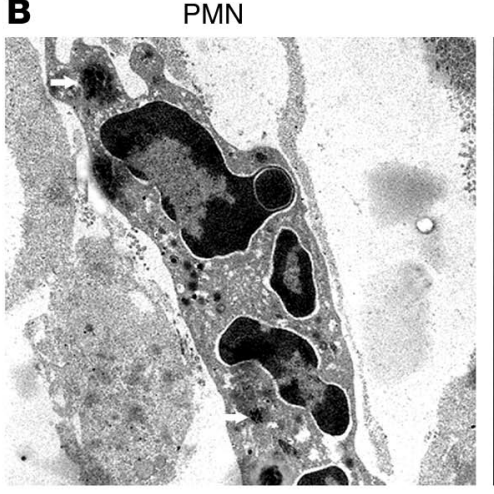

E

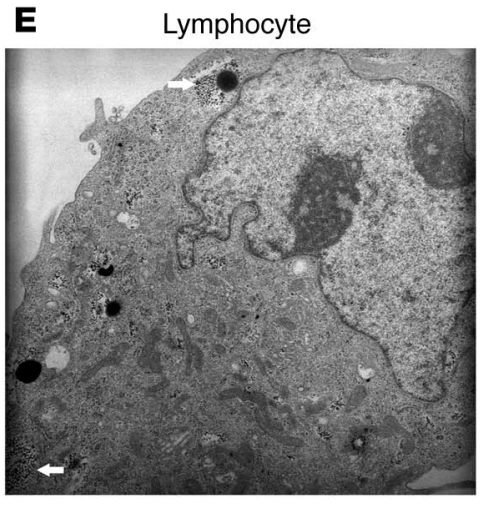

C Lymphocyte

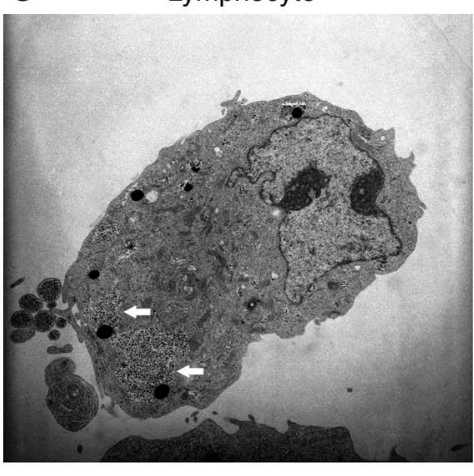

\section{Figure 5}

Electron micrographs showing END immunoreactivity in inflamed paw tissue. (A) Cells were identified as macrophages (pseudopodia of various shapes, vacuolated cytoplasm containing granules, nucleus with distinctive ring of heterochromatin around its periphery; ref. 49), (B) PMNs (relative density of intramembranous particles, membranous extensions of the plasma membrane, lysosomes, and phagocytic vacuoles; ref. 50), and (C) lymphocytes (large nucleus with heterochromatin forming a peripheral rim adjacent to the nuclear envelope with deep infolding of the nuclear membrane, thick bundles of filaments in the cytoplasm; ref. 49). Labeling for END (arrows) was confined to secretory granules grouped within membranous vesicular structures in these cells. (D and $\mathbf{E}$ ) Higher magnifications of $\mathbf{A}$ and $\mathbf{C}$, showing END-labeled secretory granules within membranous vesicular structures (arrows). Original magnification, $\times 5,000(\mathbf{A}-\mathbf{C})$ and $\times 10,000(\mathbf{D}$ and $\mathbf{E})$.

Removal of immune cell-derived opioid peptides inhibits $\mu$-receptor function and restores tolerance. First we performed cAMP experiments to study the functional relevance of the observed lack of $\mu$-receptor internalization in animals with CFA inflammation and CTX treatment. Following chronic s.c. morphine treatment, acute application of morphine to DRG neurons of these animals no longer decreased FSK-stimulated cAMP, indicating that $\mu$-receptors were not fully active (ANOVA, $P>0.05$ ) (Figure 6F). In contrast to our initial findings (Figure 1B), in CTX-treated CFA animals chronic s.c. morphine shifted the dose-response curve of acute i.pl. fentanyl-induced antinociception significantly to the right (Figure $6 \mathrm{~K}$ and Table 1 ). To corroborate this finding, rats were locally pretreated with i.pl. antibodies against endogenous opioid peptides. CFA animals treated daily with s.c. morphine and a combination of i.pl. anti-END and anti-met-enkephalin developed tolerance. This was evident from a significant rightward shift of the dose-response curve of acute i.pl. fentanyl antinociception in antibody-treated versus vehicle-treated animals (Figure 6L and Table 1). Thus, immune cell-derived opioid peptides apparently counteract the development of tolerance.

\section{Discussion}

Our results demonstrate that during inflammatory pain, chronic morphine treatment does not result in antinociceptive tolerance at peripheral opioid receptors. Rather, we showed increased $\mu$-receptor endocytosis as well as intact G protein coupling and cAMP inhibition, indicating fully preserved opioid receptor function in sensory neurons. However, when endogenous ligands of these receptors were removed by treatment with CTX or antibodies, decreased $\mu$-receptor endocytosis/function and tolerance ensue.

A spectrum of cellular adaptations resulting from chronic exposure to opioids is responsible for the development of tolerance (20) in experimental animals or in human addicts (21). However, many of those previous findings were obtained in the absence of painful tissue injury. This is a shortcoming because patients usually do not consume opioids when they are not in pain, which may explain some of the discrepancies between experimental (20) and clinical $(6,22)$ studies. For this reason, we studied the development of opioid tolerance in animals with painful hindpaw inflammation, a model that resembles postoperative pain, arthritis, and other types of inflammatory pain (9). The analgesic effects of systemically applied opioid agonists can have both a peripheral and a central component of action. In injury-induced pain, a substantial component of opioid analgesia is mediated via peripheral opioid receptors $(9,10,23)$. Therefore, even in the presence of central tolerance, the peripheral component of opioid action might still produce clinically sufficient analgesia. To specifically investigate tolerance at 

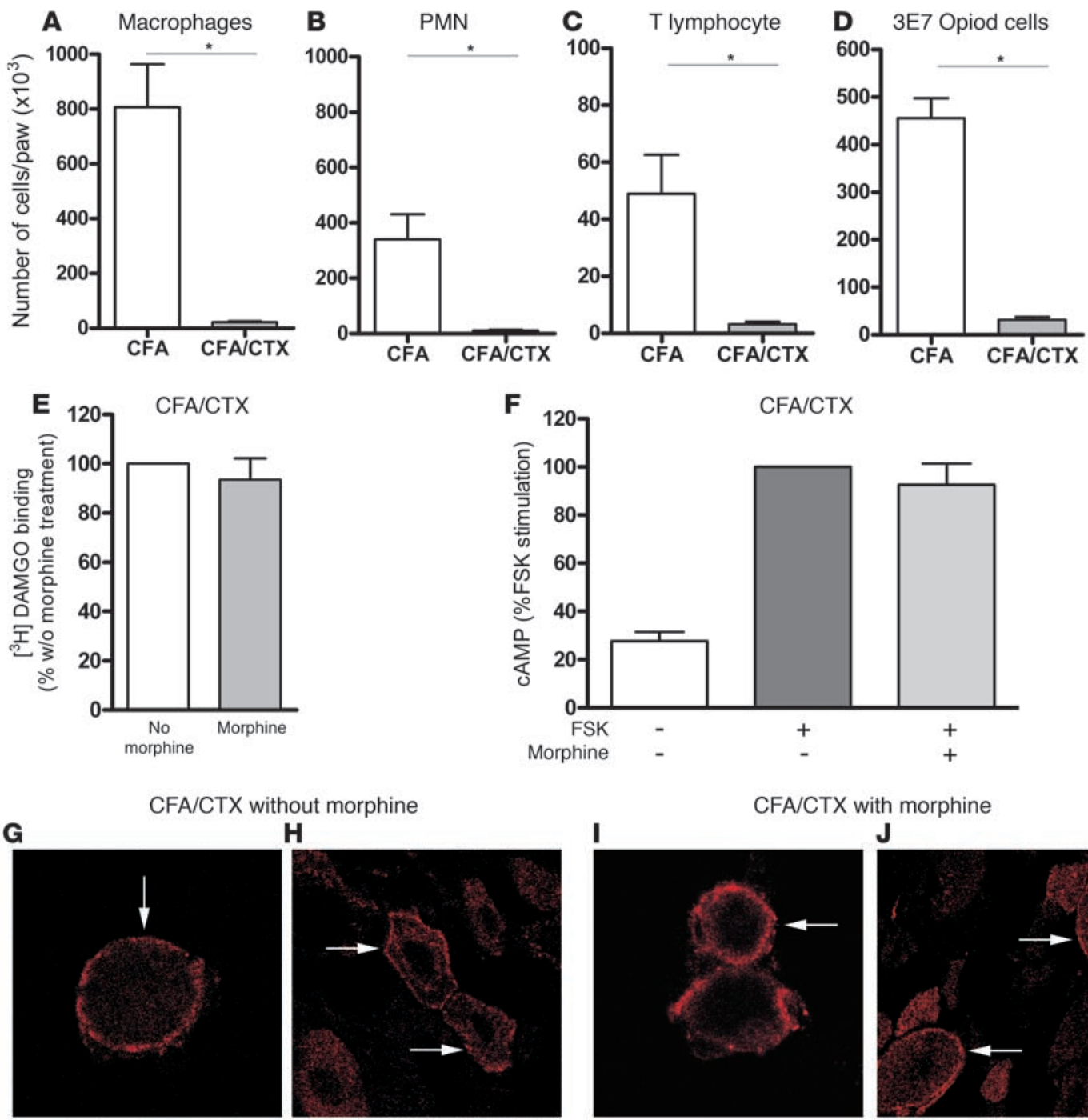

CFA/CTX
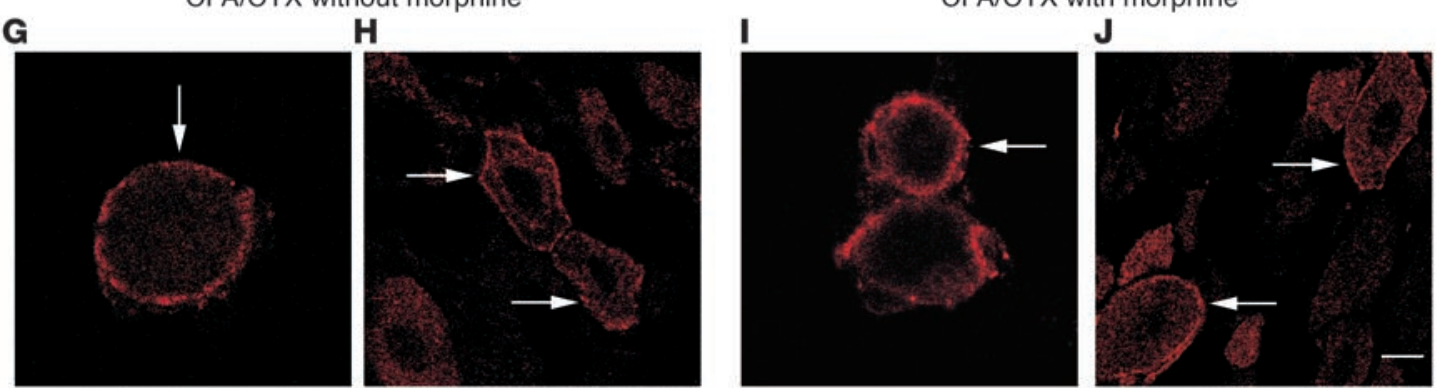

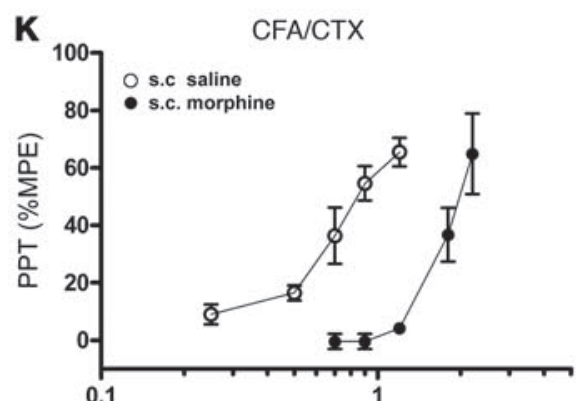

i. pl. fentanyl $(\mu \mathrm{g})$

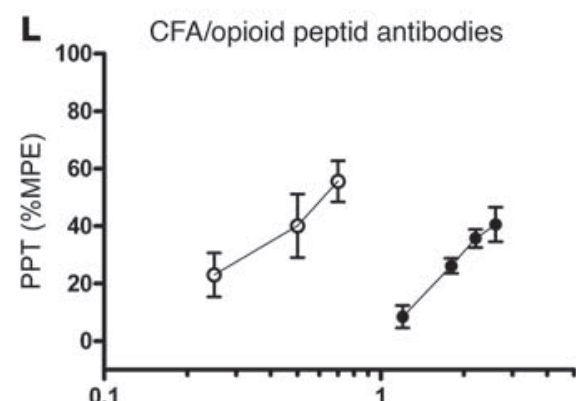

i.pl. fentanyl $(\mu \mathrm{g})$

Figure 6

Removal of immune cell-derived opioid peptides by CTX. (A-D) Quantification of immune cells in inflamed paw tissue by flow cytometry. CTX treatment depleted macrophages (A), PMNs (B), T lymphocytes (C), and opioid peptide-containing cells (D). ${ }^{*} P<0.01$. (E) $\left[{ }^{3} H\right]$ DAMGO saturation binding in DRG cells from animals with paw inflammation and CTX treatment. The number of $\mu$-receptors did not differ significantly between untreated (set at $100 \%$ ) and s.c. morphine-pretreated animals ( $t$ test, $P>0.05)$. $(F)$ Content of cAMP in DRG cells from CFA animals with CTX treatment. Acute opioid application $(+/+)$ did not decrease FSK-stimulated cAMP production (+/-) after chronic s.c. morphine pretreatment (ANOVA, $P>0.05)$. Values are expressed as percentages of FSK-stimulated (100\%) cAMP levels. (G, H, I, and $\mathbf{J})$ Confocal laser scanning microscopy of cultured DRG cells ( $G$ and $\mathbf{I}$ ) and native DRG sections ( $\mathbf{H}$ and $\mathbf{J}$ ) obtained from CFA animals immunosuppressed with $\mathrm{CTX}$. Immunohistochemically labeled $\mu$-receptors are primarily localized to the plasma membrane in animals treated with vehicle $(\mathbf{G}$ and $\mathbf{H})$ and with chronic s.c. morphine $(\mathbf{I}$ and $\mathbf{J})$ Scale bar: $5 \mu \mathrm{M}(\mathbf{G}$ and $\mathbf{~ I ) ; ~} 10 \mu \mathrm{M}(\mathbf{H}$ and $\mathbf{J})$. ( $\mathbf{K}$ and $\mathbf{L}$ ) Dose-response curves of acute i.pl. fentanyl antinociception in CFA animals immunosuppressed with CTX (K) or injected with i.pl. opioid peptide antibodies (L) with and without chronic s.c. morphine pretreatment. In both conditions the ED ${ }_{50}$ for elevation of PPT was significantly lower without than with s.c. morphine pretreatment (see Table 1) (CTX: $t$ test, $P<0.05$; opioid peptide antibodies: $t$ test, $P<0.01$ ). 
peripheral opioid receptors, we used acute local (i.pl.) injections of small, systemically ineffective doses of fentanyl. This precludes that the behavioral effects were affected by central neural circuits. Previous studies $(24,25)$ and our current behavioral experiments have shown that in animals without tissue injury chronic opioid treatment can induce profound tolerance at peripheral $\mu$-receptors within several days. However, in the presence of painful inflammation, we did not find such tolerance in vivo. This is in contrast to a recent study by Fernandez-Duenas et al. (26), in which the antinociceptive potency of acutely administered s.c. morphine decreased more pronouncedly in mice with CFA inflammation than in mice without inflammation. However, apart from the species difference, in the latter study s.c. morphine pellets were implanted 4 days after i.pl. CFA inoculation. Thus, the tissue injury commenced 4 days before the animals began to receive morphine and it is conceivable that the conditions for intraneuronal opioid receptor trafficking and signaling (e.g., cAMP upregulation) were different after these 4 days of ongoing inflammation without morphine treatment. We aimed to mimic the clinical situation by initiating morphine treatment simultaneously with the onset of tissue injury. In addition, changes in the antinocieptive potency of s.c. morphine might have been due to events at supraspinal, spinal, and peripheral levels, since naloxone-methiodide (a peripherally restricted opioid receptor antagonist) did not completely abolish the acute morphine effects in Fernandez-Duenas's experiments. In contrast, we used a specific dose range of i.pl. fentanyl that only acted peripherally. Thus, our study examines mechanisms at the level of the peripheral sensory neuron exclusively. In line with our findings, a previous study in rats receiving formalin injections into the paw (27) and clinical studies in patients with non-cancer pain (reviewed in ref. 28) have suggested that the treatment of inflammatory pain with opioids is not necessarily associated with the development of pharmacological tolerance. However, the underlying molecular mechanisms of these unexpected effects have not been elucidated so far.

A fundamental mechanism of opioid receptor regulation involves rapid endocytosis of receptors via clathrin-coated pits and functional resensitization (20). Our studies of $\mu$-receptor redistribution in DRG cells support previous observations that morphineactivated receptors are relatively resistant to rapid endocytosis in cultured cells and native neurons $(14,15)$, although morphine is highly efficient in inducing tolerance in healthy animals. It was suggested that this failure of $\mu$-receptor endocytosis contributes to the development of tolerance and dependence (29). These findings led to the current hypothesis that $\mu$-receptor endocytosis and recycling even prevent the development of tolerance $(13,30)$. Using a well-characterized cell culture model, it was shown that opioid receptor mutations that facilitate receptor endocytosis can attenuate, whereas blocking endocytosis can exacerbate, the development of morphine tolerance (2). In our animals with CFA inflammation, chronic morphine pretreatment was associated with enhanced $\mu$-receptor endocytosis and redistribution toward the intracellular compartment, consistent with the notion that a reduction of surface receptors is not necessarily connected to tolerance and that endocytosis serves a protective role and reduces the development of tolerance in an inflammatory painful condition.

Tolerance to morphine may also occur as a result of opioid receptor desensitization or receptor downregulation (i.e., a reduction of total receptor number). We examined the basis for the apparent protective effect of inflammation against opioid tolerance by investigating downstream signaling mechanisms. Previous studies have shown that a decrease in $G$ protein coupling to $\mu$-receptors can substantially contribute to the development of opioid tolerance (31). Indeed, we found a significant decrease in the number of $G$ proteins activated per $\mu$-receptor (amplification factor) in the DRG of opioid-tolerant animals without inflammation. In contrast, both $\mu$-receptor-stimulated $G$ protein levels and surface $\mu$-receptor numbers decreased to the same degree (unchanged amplification factor) in nontolerant animals with CFA inflammation. This suggests that, in noninjured animals, chronic morphine pretreatment promotes receptor-G protein uncoupling but does not change surface receptor number (i.e., there is no endocytosis). In CFA-treated animals morphine pretreatment decreases surface receptor number (because of endocytosis) but the receptors remaining on the surface stay coupled.

Inhibition of adenylyl cyclase-mediated cAMP formation is a hallmark of the cellular actions of opioids (32). Acute activation of $\mathrm{G \alpha}_{\mathrm{i}}$-coupled opioid receptors typically inhibits cAMP accumulation, but after withdrawal of ongoing opioid treatment adenylyl cyclase activity can be enhanced (33). This compensatory superactivation in the adenylyl cyclase pathway may contribute to tolerance (32). Our experiments indicate that the acute inhibitory effect of morphine on cAMP formation in DRG cells did not differ between animals with and without CFA inflammation. However, in line with previous studies (34), the absolute content of cAMP after FSK was significantly higher in animals treated with CFA (data not shown). Thus it is reasonable to assume that, consistent with the increased number of $\mu$-receptors, the acute inhibitory effect of morphine in fact increases but, due to a parallel increase in cAMP during inflammation, the relative effect is similar to that in noninjured animals. After chronic morphine pretreatment, the ability of acutely applied opioids to inhibit adenylyl cyclase was abolished in DRG of rats without CFA inflammation, but was preserved in animals with inflammation. Together with our quantitative opioid receptor binding assay, this indicates that despite chronic morphine treatment, more functionally active receptors are available on DRG neurons in animals with compared with animals without inflammation. Hence it appears that during paw inflammation enhanced opioid receptor internalization restores the functionality of $\mu$-receptors on DRG neurons and thus decreases the development of behavioral tolerance.

Several studies have shown that opioid receptors are particularly rapidly internalized after activation by their native peptide ligands $(14,35)$. All physiologically expressed opioids tested so far produce $\mu$-receptor internalization (36). Furthermore, it has been proposed that opioid peptides, even at subanalgesic doses, can facilitate the ability of morphine to stimulate $\mu$-receptor endocytosis and can reduce the development of morphine tolerance $(37,38)$. Although other groups have failed to detect this effect in vitro $(13,39)$, in vivo experiments in healthy animals have shown that simultaneous treatment with morphine and opioid peptides reduced analgesic tolerance $(38,40)$. We and others found that endogenous opioid peptides are expressed and released in inflamed tissue from immune cells in the periphery. Immune cells migrate from the circulation to inflamed tissue and release opioid peptides (9). In the present study, we used electron microscopy to identify END-containing cells as macrophages, PMNs, and lymphocytes. To study the role of such immune cell-derived opioids in tolerance, we applied CTX, an alkylating agent widely used for immunosuppression (41). CTX successfully depleted PMNs, macrophages, Tlymphocytes, and opi- 
oid peptide-containing cells in the inflamed tissue. In these animals, chronic morphine-induced desensitization of $\mu$-receptors and behavioral signs of tolerance were restored. This was corroborated by an additional experiment, in which animals receiving repeated local injections of opioid peptide antibodies developed behavioral signs of tolerance. In line with studies showing that inflammatory pain (42) or the release of endogenous opioid peptides in the spinal cord (36) can increase opioid receptor internalization in vivo, our results thus indicate that the lack of tolerance and enhanced recycling/resensitization of opioid receptors in sensory neurons is due to the tonic release of endogenous opioid peptides from resident PMNs, macrophages, and lymphocytes within inflamed paws.

In summary, experimental studies on opioid tolerance are often performed in the absence of painful tissue injury, which precludes extrapolation to the clinical situation. In the current investigation, we found that persistent painful inflammation prevents the development of tolerance at peripheral opioid receptors by enhancing $\mu$-receptor endocytosis, recycling, and recovery of opioid responsiveness after prolonged morphine treatment. Our data indicate that the release of endogenous opioid peptides from inflammatory cells can facilitate the ability of exogenous opioids to stimulate $\mu$-receptor endocytosis in sensory neurons and thereby reduce the development of morphine tolerance. This is consistent with the notion that opioids promoting receptor endocytosis (e.g., endogenous opioid peptides) prevent tolerance induction by non-internalizing opioid agonists (e.g., morphine) and that cross-tolerance occurs more likely when different non-internalizing opioid receptor ligands are used. Our findings infer that the use of peripherally acting opioid agonists for the prolonged treatment of inflammatory pain, such as pain associated with chronic arthritis, inflammatory neuropathy, or cancer, is not necessarily accompanied by opioid tolerance. In addition, our data help to elucidate the hitherto enigmatic discrepancies between experimental and clinical observations on opioid tolerance. Because peripherally acting opioid analgesics have attracted much interest and have become increasingly relevant in daily clinical practice, uncovering mechanisms determining tolerance at peripheral opioid receptors will hopefully open new avenues for pain research and therapy.

\section{Methods}

Subjects. Experiments were performed using individually housed male Wistar rats $(180-200 \mathrm{~g})$. The animal protocol was approved by the state animal care and use committee (Landesamt für Arbeitsschutz, Gesundheit und Technische Sicherheit Berlin), and the guidelines on ethical standards for investigations of experimental pain in animals were followed. All i.pl. injections were performed under brief isoflurane (Willy Rüsch $\mathrm{GmbH}$ ) anesthesia.

Induction of paw inflammation and chronic opioid pretreatment. All chemicals and drugs were purchased from Sigma-Aldrich unless otherwise indicated. Control animals were treated with s.c. saline injections (twice/day) for 4 days. Chronic opioid pretreatment was performed by injection of morphine (Merck; $10 \mathrm{mg} / \mathrm{kg}$ body weight) s.c. twice/day (8 am and $6 \mathrm{pm}$ ) in the back of the animals from day 1 through day 4 . On day 5 animals were injected once with morphine (s.c.), and behavioral experiments were performed 3 hours later. On day 1 inflammation was induced using $0.15 \mathrm{ml}$ of CFA (Calbiochem) administered i.pl. into the right hind paw. In separate experiments ( $n=6-8 \mathrm{rats} /$ group), fentanyl ( $2 \mu \mathrm{g}$ ) was injected into the plantar surface of the hindpaw (i.pl.) twice/day ( 8 am and $6 \mathrm{pm}$ ) from day 1 through day 4 to induce tolerance. On day 5 animals were injected once with i.pl. fentanyl, and behavioral experiments were performed 3 hours later as described.
CTX treatment. CTX (Endoxan) (Baxter Oncology) was dissolved in sterile distilled water to a concentration of $25 \mathrm{mg} / \mathrm{ml}$ and injected i.p. 72 hours (100 mg/kg body weight) and 24 hours $(50 \mathrm{mg} / \mathrm{kg}$ body weight) prior to CFA treatment. An additional injection was performed 24 hours $(25 \mathrm{mg} / \mathrm{kg}$ body weight) after CFA injection.

Antibody treatment against opioid peptides. Antibodies (Bachem) were injected i.pl. into the inflamed paw once daily for 4 days. Based on our previous study (43), the most effective i.pl. doses of anti-END $(2 \mu \mathrm{g})$ and anti-metenkephalin $(0.25 \mu \mathrm{g})$ were combined in a total volume of $0.1 \mathrm{ml}$. Control animals received rabbit IgG $(8 \mu \mathrm{g})$ i.pl. in a volume of $0.1 \mathrm{ml}$.

Measurement of PPT. Mechanical nociceptive thresholds were assessed in rats ( $n=6-8$ per group) 3 hours after saline/morphine injection and before (baseline) and after i.pl. administration of the $\mu$-receptor agonist fentanyl (JanssenCilag) (in $100 \mu \mathrm{l}$ ) using the paw pressure algesiometer (modified Randall-Selitto test; Ugo Basile). Control animals received i.pl. saline in the same volume. The pressure required to elicit paw withdrawal, the PPT (cutoff at $250 \mathrm{~g}$ ), was determined immediately after fentanyl injection by averaging 3 consecutive trials separated by $10 \mathrm{~s}$. The sequence of left and right paws was alternated between animals to avoid bias. The experimenter was blind to the treatment.

Membrane preparations. Membranes were prepared as described (44). Briefly, rats were killed and lumbar (L3-L5) DRG were removed. The tissue was placed immediately on ice in cold assay buffer $(50 \mathrm{mM}$ Tris- $\mathrm{HCl}, 1 \mathrm{mM}$ EGTA, pH 7.4) Tissue was homogenized and centrifuged at 42,000 $\mathrm{g}$ and $4^{\circ} \mathrm{C}$ for $20 \mathrm{~min}$. The pellet was resuspended in assay buffer followed by a 10 -min incubation at $37^{\circ} \mathrm{C}$ to degrade endogenous ligands. The homogenate was centrifuged again at 42,000 $\mathrm{g}$ and resuspended in assay buffer.

Cultures of DRG neurons. DRG (L3-L5) were removed and placed in sterile modified MEM (Biochrom AG) at $4^{\circ} \mathrm{C}$. DRG were digested with collagenase type $2\left(37^{\circ} \mathrm{C}\right.$ for $\left.50 \mathrm{~min}\right)$ and trypsin $\left(37^{\circ} \mathrm{C}\right.$ for $\left.10 \mathrm{~min}\right)$. After digestion, DRG were centrifuged at $500 \mathrm{~g}$ for $5 \mathrm{~min}$ and at $300 \mathrm{~g}$ for another $5 \mathrm{~min}$. The cells were maintained for $1 \mathrm{~h}$ in MEM growth media supplemented with $10 \%$ horse serum, $50 \mu \mathrm{g} / \mathrm{ml}$ penicillin and streptomycin.

Saturation $\mu$-receptor binding. Plasma membranes from DRG neurons were prepared as described (44). Saturation binding was performed using the $\mu$-receptor ligand $\left[{ }^{3} \mathrm{H}\right] \mathrm{DAMGO}(0.02-2 \mathrm{nM})(65 \mathrm{Ci} / \mathrm{mmol}$; Amersham Pharmacia Biotech) to determine $\mathrm{K}_{\mathrm{d}}$ and $\mathrm{B}_{\max \mu \text {-receptor. See Supplemental }}$ Methods online for more details.

${ }^{[35}$ S GTP $\gamma$ S saturation binding at $\mu$-receptors. Saturation analysis of DAMGOstimulated [ $\left.{ }^{35} \mathrm{~S}\right]$ GTP $\gamma \mathrm{S}$ (1250 Ci/mmol; New England Nuclear Corp.) binding was used as previously described (45) to determine the apparent $\mathrm{K}_{\mathrm{d}}$ of $\left[{ }^{35} \mathrm{~S}\right] \mathrm{GTP} \gamma \mathrm{S}$ for the activated $\mathrm{G} \alpha$-subunit (apparent $\mathrm{K}_{\mathrm{d}} \mathrm{G}$ protein) and the apparent $B_{\max } G$ protein. The relative amplification factor $\left(B_{\max } G\right.$ protein $/ B_{\max } \mu$-receptor $)$ was calculated according to methods described in ref. 45 and represents the number of $G$ proteins activated per $\mu$-receptor. See Supplemental Methods online for more details.

cAMP accumulation. cAMP accumulation was measured immediately after dissociation of DRG cells. Cells were incubated for $20 \mathrm{~min}$ in the presence of $50 \mathrm{mM}$ Tris $(1 \mathrm{ml})$ containing the phosphodiesterase inhibitor isobuthylmethylxanthine $(2 \mathrm{mM})$ and FSK $(1 \mu \mathrm{M})$. Acute opioid effects were determined by incubating cells with morphine $(10 \mu \mathrm{M})$ for $15 \mathrm{~min}$. Following this incubation, cells were homogenized and boiled for $3 \mathrm{~min}$. The cell suspension was centrifuged at 4,000 $\mathrm{g}$ for $4 \mathrm{~min}$. The levels of cAMP in the supernatant were determined by a $\left[{ }^{3} \mathrm{H}\right]$ cAMP assay kit $(5 \mu \mathrm{Ci}$; Amersham Pharmacia Biotech) as previously described (46).

Immunofluorescence. Immunofluorescence imaging of DRG neurons was performed in cultures and sections as described previously (47). See Supplemental Methods online for more details.

Immunoelectron microscopy. Immunoelectron microscopy in hindpaws of animals with CFA inflammation was performed as described previously (18). See Supplemental Methods online for more details. 
Flow cytometry. Cells suspensions from inflamed hindpaws were prepared and stained as described previously (48). See Supplemental Methods online.

Statistics. Data are expressed as means \pm SEM. Unpaired 2-tailed Student's $t$ test and 1-way ANOVA were performed for statistical comparisons. For all tests, a $P$ value of less than 0.05 was considered to be significant. See Supplemental Methods online for more details.

\section{Acknowledgments}

This work was supported by DFG grant KFO 100. We thank P. Heppenstall for critical reading and comments on the manuscript, N. Siegemund for technical assistance, and S. Schulz and V. Höllt for $\mu$-receptor antibodies.
Received for publication June 9, 2005, and accepted in revised form November 28, 2007.

Address correspondence to: Christian Zöllner, Klinik für Anaesthesiologie und operative Intensivmedizin, Charité-Universitätsmedizin Berlin, Campus Benjamin Franklin, Hindenburgdamm 30, 12200 Berlin, Germany. Phone: 49-30-8445-3678; Fax: 49-308445-4469; E-mail: christian.zoellner@charite.de.

Waltraud Binder's present address is: School of Physiology and Pharmacology, University of New South Wales, Sydney, New South Wales, Australia.
1. Bohn, L.M., Gainetdinov, R.R., Lin, F.T., Lefkowitz, R.J., and Caron, M.G. 2000. Mu-opioid receptor desensitization by beta-arrestin- 2 determines morphine tolerance but not dependence. Nature. 408:720-723.

2. Finn, A.K., and Whistler,J.L. 2001. Endocytosis of the mu opioid receptor reduces tolerance and a cellular hallmark of opiate withdrawal. Neuron. 32:829-839.

3. Carroll, I.R., Angst, M.S., and Clark, J.D. 2004. Management of perioperative pain in patients chronically consuming opioids. Reg. Anesth. Pain Med. 29:576-591.

4. Furlan, A.D., Sandoval, J.A., Mailis-Gagnon, A., and Tunks, E. 2006. Opioids for chronic noncancer pain: a meta-analysis of effectiveness and side effects. CMAJ. 174:1589-1594.

5. Portenoy, R.K., Moulin, D.E., Rogers, A., Inturrisi, C.E., and Foley, K.M. 1986. I.v. infusion of opioids for cancer pain: clinical review and guidelines for use. Cancer Treat. Rep. 70:575-581.

6. Zech, D.F., Grond, S., Lynch, J., Hertel, D., and Lehmann, K.A. 1995. Validation of World Health Organization Guidelines for cancer pain relief: a 10-year prospective study. Pain. 63:65-76.

7. Adriaensen, H., Vissers, K., Noorduin, H., and Meert, T. 2003. Opioid tolerance and dependence: an inevitable consequence of chronic treatment? Acta. Anaesthesiol. Belg. 54:37-47.

8. Portenoy, R.K. 2004. Appropriate use of opioids for persistent non-cancer pain. Lancet. 364:739-740.

9. Stein, C., Schäfer, M., and Machelska, H. 2003. Attacking pain at its source: new perspectives on opioids. Nat. Med. 9:1003-1008.

10. Tegeder, I., et al. 2003. Peripheral opioid analgesia in experimental human pain models. Brain. 126:1092-1102.

11. Drake, M.T., Shenoy, S.K., and Lefkowitz, R.J. 2006. Trafficking of $\mathrm{G}$ protein-coupled receptors. Circ. Res. 99:570-582.

12. Qiu, Y., Law, P.Y., and Loh, H.H. 2003. Mu-opioid receptor desensitization: role of receptor phosphorylation, internalization, and representation. J. Biol. Chem. 278:36733-36739.

13. Koch, T., et al. 2005. Receptor endocytosis counteracts the development of opioid tolerance. $\mathrm{Mol}$. Pharmacol. 67:280-287.

14. Keith, D.E., et al. 1996. Morphine activates opioid receptors without causing their rapid internalization. J. Biol. Chem. 271:19021-19024.

15. Sternini, C., et al. 1996. Agonist-selective endocytosis of mu opioid receptor by neurons in vivo. Proc. Natl. Acad. Sci. U. S. A. 93:9241-9246.

16. Yu, Y., et al. 1997. Mu opioid receptor phosphorylation, desensitization, and ligand efficacy. J. Biol. Chem. 272:28869-28874.

17. Schulz, S., et al. 2004. Morphine induces terminal muopioid receptor desensitization by sustained phosphorylation of serine-375. EMBOJ. 23:3282-3289.

18. Mousa, S.A., Shakibaei, M., Sitte, N., Schafer, M., and Stein, C. 2004. Subcellular pathways of betaendorphin synthesis, processing, and release from immunocytes in inflammatory pain. Endocrinology.
145:1331-1341.

19. Antonijevic, I., Mousa, S.A., Schäfer, M., and Stein, C. 1995. Perineurial defect and peripheral opioid analgesia in inflammation. J. Neurosci. 15:165-172.

20. Williams, J.T., Christie, M.J., and Manzoni, O. 2001. Cellular and synaptic adaptations mediating opioid dependence. Physiol. Rev. 81:299-343.

21. Kissin, I. 2005. Tolerance to opioid analgesia: why do we differ from rats? Anesth. Analg. 101:1727-1729.

22. Gutstein, H.B. 1996. The effects of pain on opioid tolerance: how do we resolve the controversy? Pharmacol. Rev. 48:403-407.

23. Kayser, V., Chen, Y.L., and Guilbaud, G. 1991. Behavioural evidence for a peripheral component in the enhanced antinociceptive effect of a low dose of systemic morphine in carrageenin-induced hyperalgesic rats. Brain Res. 560:237-244.

24. Aley, K.O., Green, P.G., and Levine, J.D. 1995. Opioid and adenosine peripheral antinociception are subject to tolerance and withdrawal. J. Neurosci. 15:8031-8038.

25. Kolesnikov, Y., and Pasternak, G.W. 1999. Topical opioids in mice: analgesia and reversal of tolerance by a topical N-methyl-D-aspartate antagonist. J. Pharmacol. Exp. Ther. 290:247-252.

26. Fernandez-Duenas, V., et al. 2007. Tolerance to the antinociceptive and antiexudative effects of morphine in a murine model of peripheral inflammation. J. Pharmacol. Exp. Ther. 322:360-368.

27. Vaccarino, A.L., et al. 1993. Morphine fails to produce tolerance when administered in the presence of formalin pain in rats. Brain Res. 627:287-290.

28. Kalso, E., Edwards, J.E., Moore, R.A., and McQuay, H.J. 2004. Opioids in chronic non-cancer pain: systematic review of efficacy and safety. Pain. 112:372-380.

29. Whistler, J.L., Chuang, H.H., Chu, P., Jan, L.Y., and von Zastrow, M. 1999. Functional dissociation of mu opioid receptor signaling and endocytosis: implications for the biology of opiate tolerance and addiction. Neuron. 23:737-746.

30. Ferguson, S.S. 2001. Evolving concepts in G protein-coupled receptor endocytosis: the role in receptor desensitization and signaling. Pharmacol. Rev. 53:1-24.

31. Sim-Selley, L.J., Selley, D.E., Vogt, L.J., Childers, S.R., and Martin, T.J. 2000. Chronic heroin selfadministration desensitizes mu opioid receptoractivated G-proteins in specific regions of rat brain. J. Neurosci. 20:4555-4562.

32. Kim, K.S., et al. 2006. Adenylyl cyclase type 5 (AC5) is an essential mediator of morphine action. Proc. Natl. Acad. Sci. U. S. A. 103:3908-3913.

33. Nestler, E.J., and Aghajanian, G.K. 1997. Molecular and cellular basis of addiction. Science. 278:58-63.

34. Bolyard, L.A., Van Looy, J.W., and Vasko, M.R. 2000. Sensitization of rat sensory neurons by chronic exposure to forskolin or 'inflammatory cocktail' does not downregulate and requires continuous exposure. Pain. 88:277-285.

35. Keith, D.E., et al. 1998. mu-Opioid receptor inter- nalization: opiate drugs have differential effects on a conserved endocytic mechanism in vitro and in the mammalian brain. Mol. Pharmacol. 53:377-384.

36. Song, B., and Marvizon, J.C. 2003. Peptidases prevent mu-opioid receptor internalization in dorsal horn neurons by endogenously released opioids. J. Neurosci. 23:1847-1858.

37. He, L., and Whistler, J.L. 2005. An opiate cocktail that reduces morphine tolerance and dependence. Curr. Biol. 15:1028-1033.

38. Hashimoto, T., et al. 2006. Enhancement of morphine analgesic effect with induction of mu-opioid receptor endocytosis in rats. Anesthesiology. 105:574-580.

39. Bailey, C.P., et al. 2003. Mu-opioid receptor desensitization in mature rat neurons: lack of interaction between DAMGO and morphine. J. Neurosci. 23:10515-10520.

40. He, L., Fong, J., von Zastrow, M., and Whistler, J.L. 2002. Regulation of opioid receptor trafficking and morphine tolerance by receptor oligomerization. Cell. 108:271-282.

41. Muranski, P., et al. 2006. Increased intensity lymphodepletion and adoptive immunotherapy - how far can we go? Nat. Clin. Pract. Oncol. 3:668-681.

42. Gendron, L., et al. 2006. Morphine and pain-related stimuli enhance cell surface availability of somatic delta-opioid receptors in rat dorsal root ganglia. J. Neurosci. 26:953-962.

43. Machelska, H., et al. 2003. Different mechanisms of intrinsic pain inhibition in early and late inflammation. J. Neuroimmunol. 141:30-39.

44. Zöllner, C., et al. 2003. Painful inflammationinduced increase in mu-opioid receptor binding and G-protein coupling in primary afferent neurons. Mol. Pharmacol. 64:202-210.

45. Shaqura, M.A., Zöllner, C., Mousa, S.A., Stein, C., and Schäfer, M. 2004. Characterization of mu opioid receptor binding and $G$ protein coupling in rat hypothalamus, spinal cord, and primary afferent neurons during inflammatory pain. J. Pharmacol. Exp. Ther. 308:712-718.

46. Zaki, P.A., Keith, D.E., Jr., Brine, G.A., Carroll, F.I., and Evans, C.J. 2000. Ligand-induced changes in surface mu-opioid receptor number: relationship to G protein activation? J. Pharmacol. Exp. Ther. 292:1127-1134.

47. Mousa, S.A., Zhang, Q., Sitte, N., Ji, R., and Stein, C. 2001. beta-Endorphin-containing memory-cells and mu-opioid receptors undergo transport to peripheral inflamed tissue. J. Neuroimmunol. 115:71-78.

48. Rittner, H.L., et al. 2006. Pain control by CXCR2 ligands through $\mathrm{Ca} 2+$-regulated release of opioid peptides from polymorphonuclear cells. FASEB J. 20:2627-2629.

49. Abe, K., Honma, S., and Ito, T. 1981. Peritoneal free cells in mice, examined by transmission electron microscopy in thick sections. J. Electron Microsc. (Tokyo) 30:141-147.

50. Poole, J.C. 1969. Electron microscopy of polymorphonuclear leucocytes. Br. J. Dermatol. 81(Suppl. 3):11-18. 